\title{
Violent and Risk-Taking Behaviors Associated with Intake of Energy Drinks Mixed with Alcohol and Perceptions of This Consumption among Children and Adolescents in Costa Rica
}

\author{
Núñez-Rivas Hilda ${ }^{1}$, Holst-Schumacher Ileana ${ }^{2 *}$, Campos-Saborío Natalia ${ }^{3}$ \\ ${ }^{1}$ Costa Rican Institute of Research and Education in Health and Nutrition (INCIENSA), Tres Ríos, Costa Rica \\ ${ }^{2}$ University of Costa Rica (UCR), San Pedro Montes de Oca, Costa Rica \\ ${ }^{3}$ State University at Distance (UNED), Sabanilla, Costa Rica \\ Email:hnunez@inciensa.sa.cr, ${ }^{\star}$ Ileana.holst@ucr.ac.cr, nataliacampos07@yahoo.com
}

How to cite this paper: Hilda, N.-R., Ileana, H.-S. and Natalia, C.-S. (2020) Violent and Risk-Taking Behaviors Associated with Intake of Energy Drinks Mixed with Alcohol and Perceptions of This Consumption among Children and Adolescents in Costa Rica. Food and Nutrition Sciences, 11, 836-853. https://doi.org/10.4236/fns.2020.118059

Received: July 28, 2020

Accepted: August 25, 2020

Published: August 28, 2020

Copyright (อ 2020 by author(s) and Scientific Research Publishing Inc. This work is licensed under the Creative Commons Attribution-NonCommercial International License (CC BY-NC 4.0). http://creativecommons.org/licenses/by-nc/4.0/ (c) (i) (5) Open Access

\begin{abstract}
Introduction: The consumption of energy drinks and its mix with alcohol has been associated with negative and violent behaviors in youngsters. Objective: To determine the risk-taking behaviors associated with the consumption of energy drinks mixed with alcohol in Costa Rican adolescents. Methods: A mixed cross-sectional study was performed with a population of 2667 students of 64 educative centers in 2016. Descriptive statistics were performed with the program SPSS 20.0 and a value of $p<0.05$ was considered significant. Results: The third part of the study population is usually a consumer of energy drinks (30\%) and 3\% make use of drinks mixed with alcohol. The children and adolescents, who consume energy-alcohol mixed drinks, are more likely to present risk-taking behaviors than those who do not consume these mixed beverages: combined use of medicines to get high; cocaine consumption, consumption of cement/glue, consumption of marijuana, physical violence (fighting), use of weapons, suicidal ideation, deliberate self-harm, low educational expectation, sexual intercourses, cyberbullying and school apathy. The students perceived the intake of energy beverages as of low risk for their health. They also agree that frequent consumption is because drinks have good flavors and nice logo designs and the ability to stay awake and with more energy for longer periods of time in order to improve in academic homework, sports performance and to endure more the consumption of alcoholic beverages. Conclusions: Public health policies should consider controlling the publicity aimed to children and adolescents regarding the marketing of energy and alcoholic drinks.
\end{abstract}


Keywords

Energy Drinks, Energy-Alcohol Mix Drinks, Children, Adolescents, Costa Rica

\section{Introduction}

Energy drinks are sodas with high caffeine content (some have up to $505 \mathrm{mg}$ of caffeine per serving), sugar and some vitamins such as riboflavin, pyridoxine, nicotinamide and others of the B-complex, among other substances that could act as stimulants [1] [2]. Energy drinks have been increasingly consumed, especially among teenagers, to simply enjoy their flavor or celebrate a special occasion with alcohol [3] and to maintain alertness and increase energy [4]. However, the effects of these beverages on reducing fatigue and increasing energy are controversial and their effects last a short time [1]. Several studies have reported fatal consequences of caffeine abuse and even suicide attempts in people with high concentrations of caffeine in the blood [5] [6]. Ogawa and Ueki [7] reported associations between the consumption of sweetened and energetic beverages and their mixture with alcohol and some violent and undesirable behaviors of high risk for the human health.

Children and adolescents are very susceptible to the adverse effects of caffeine on health, due to their lower substance tolerance, lower body surface area and less effective metabolic excretion capacity [8]. Likewise, young people are vulnerable to emotional changes, behavioral problems (for example, being perpetrators or victims of bullying) and a heavy workload of school work [9]. This could affect the mental health of students in schools and high schools. The occurrence of erectile dysfunction has also been reported, due to the consumption of energy drinks in combination with alcohol, which could lead children and adolescents to undergo a series of risky behaviors of sexual type, deliberate injuries and increase in the consumption of legal and illegal drugs [10] [11]. Existing evidence about the health problems associated with energy drinks and alcohol intake separately suggests that these vulnerable population groups have an increased risk for cardiovascular problems, diabetes [9] [12], sleeping disorders [8], attention deficit and hyperactivity, in addition to violent behaviors, predisposition to commit crime [13] [14] and use of harmful substances for health [4] [15].

Currently in Costa Rica, little is known about the intake of energy drinks and their mix with alcohol among children and adolescents. There is also a knowledge gap about the perceptions about the marketing of these beverages among these population groups and if they notice, use and understand the label information and the caution statements (health risks) of their consumption. This study of mixed design used a representative sample of students aged 7 to 18 years of Costa Rica and it examined the association between the intake of 
energy/energy-alcohol drinks and the adverse behaviors for health in children and adolescents. It also explores the reasons and perceptions/attitudes of this consumption among children and adolescents, considering the nutritional label of these beverages. Informants were involved in discussions about their experiences, understanding, reasons and perceptions about the marketing and intake of energy drinks. This is the first study of mixed design in Latin Ameri$\mathrm{ca}$, which examines the quantitative associations between the intakes of energy/energy-alcohol drinks with adverse health risk-taking behaviors.

\section{Materials and Methods}

\subsection{Type of Study}

Cross-sectional mixed study with emphasis on the quantitative approach carried out in 2016. The first phase was descriptive-quantitative and the second phase was qualitative with the application of focus groups.

\subsection{Population Estimate and Selection}

\section{Quantitative phase:}

The population was composed of students of elementary and middle education (I and II cycles) and high school (III cycle) from public, private and subsidized educational centers. The sample size was calculated using the proportional estimation formula, with a confidence level of $95 \%$ and an error range of $3 \%$. A total of 2667 students were selected from 64 educative centers ( 40 schools and 24 high schools) in the seven provinces of Costa Rica. In each educative center near 42 children and adolescents were randomly selected. Exclusion criteria included: incomplete participant information, inability to read and write, history of eating disorders, celiac disease or diabetes mellitus and alcohol or illicit drug dependence.

\section{Qualitative phase:}

After the quantitative data was analyzed, four schools and three high schools were randomly selected from the total sample of educative centers to carry out the focus groups.

\subsection{Data Collection and Analysis Techniques}

\section{Quantitative phase:}

Elementary students from first to third grade $(\mathrm{n}=389,14.6 \%)$ were interviewed individually by the researchers. The rest of the student population, from fourth to sixth grade $(\mathrm{n}=1175,44.1 \%)$ and high school $(\mathrm{n}=1103,41.4 \%)$ was given a validated and self-administered questionnaire designed by the investigators. Dichotomized answer categories were used to assess risk-taking behaviors (dependent variables) and the intake of energy/energy-alcohol drinks (independent variables) (code $0=$ no risk and very low risk, code $1=$ risk and high risk) during whole life period of time (for elementary students) and in the last 30 days (for middle and high school students). The following data was obtained: 
1) Social and demographic characteristics: sex, age and socioeconomic status of the students were determined according to the methodology described by Madrigal [16].

2) Addictive behaviors: The use of tobacco, alcohol (getting drunk), marijuana (Cannabis sativa), cement or glue inhalation and cocaine were considered to assess addictive behaviors experienced by elementary, middle and high school students. The use of medicines simultaneously with the drugs mentioned above was also asked ( $¿$ To get high, have you consumed medicines (examples: codeine syrups, Diazepan ${ }^{\oplus}$, Lorazepan ${ }^{\oplus}$, acetaminophen with codeine)?). Likewise, the perception/attitude of risk of children and adolescents to illegal drugs was explored (¿if a friend or partner offered you something to drug yourself (marijuana, cocaine or other illegal drug) would you accept?).

3) Psychological and risk-taking behaviors: they were assessed by questions to know if children and adolescents have had a difficult situation for which they have felt desires to die and if they have intentionally injured themselves (i.e.: cut themselves or swallow something to affect their health).

4) School apathy and academic achievement: questions about the unhappiness of the youngsters in the educative center were included ( $i$ Have you felt happy at your school or high school?) and educational expectation (¿Do you want to continue studying after you finished this year?). A question about the academic achievement was also included (¿How did you do in school?)

5) Violent behaviors: Questions were considered to know if children and adolescents have experienced: cyberbullying $(\dot{i}$ How many times have you spoken badly (gossip or lie) through the cell phone or Internet of a student or classmate with the intention to harm him/her? and physical violence (fighting) (¿How many times did you hit, kick or shove a student or partner with the intention of hurting him?) and the use of blades or other weapons (¿How many times have you brought a gun, a blade or other similar object similar to the educational center, with the intention of attacking anyone or to defend yourself?).

6) Risky-sexual behavior: was assessed by the question: ¿Have you had coital sex?

7) Energy/energy-alcohol drinks: questions to know if youngsters usually drink energy beverages and energy beverages mixed with alcohol were performed.

Qualitative phase:

During the last 6 months of 2016, a total of eight focus groups were made in each of the seven participating educative centers stratified by sex and age group to ensure homogeneity and to ease the debate [17] and address the objectives and hypotheses of the research. In total, 56 focus groups were held (32 in schools and 24 in high schools), each one of 6 to 7 participants. Each focus group began with questions about general knowledge of energy drinks and their marketing. Subsequently, they focused on the participants' perceptions about the effects of these beverages, the practice of mixing them with alcohol, their benefits and po- 
tential risks or health damage.

\subsection{Data Analysis}

SPSS 20.0 program for Windows (Statistical Package for the Social Sciences, IBM, Armonk, NY, USA) was used to estimate frequencies and continuous variables were described using mean and standard deviation. Chi-square $\left(\mathrm{X}^{2}\right)$ test was used to assess the significance of differences between the categorical variables. A $p$ value $<0.05$ was considered significant. To perform the bivariate analyzes, the probabilities that children and adolescents were involved in each of the adverse results studied were calculated, according to the category of consumers: consumers of energy drinks and consumers of energy-alcohol drinks; compared with non-consumers. The prevalence of each of the risk-taking behaviors studied was calculated for the total sample as well as stratified by the intake of energy drinks, energy-alcohol drinks and non-consumers of both beverages studied. Finally, logistic regression models were performed to assess the association between each risky-taking behavior studied and the independent variables. The models were run crudely and adjusted by gender, age and socioeconomic status in order to control these possible confusing variables.

The transcripts of the answers provided by the informants were encoded and analyzed with the Atlas Ti software package.

\subsection{General and Ethical Procedures}

The study protocol, the informed consent and assent form used were approved by the Scientific Ethics Committees of the institutions involved in the investigation. All procedures performed were in accordance with the Helsinki Declaration and its ethical standards.

\section{Results}

\section{Quantitative phase:}

A total of 2667 students from 64 educative centers (40 schools and 24 high schools) participated in this study. The intake frequency of energy drinks and energy-alcohol drinks is shown in Table 1. The social and demographic characteristics of the sample and the prevalence of risk-taking behaviors are shown in Table 2. Almost one third of the study population is a habitual consumer of energy drinks (29.9\%) and an important proportion (2.8\%), consumes these drinks mixed with alcohol. Of the total population, $67.3 \%(n=1794)$ are non-consumers of both types of beverages (Table 2). According to the bivariate analysis, the results show that the highest percentage of the student's population that consume energy drinks, as well as energy-alcohol beverages, are boys, are enrolled in high school and belong to high and medium socioeconomic status. The highest percentage of the study population is non-consumer of these drinks and has the following social and demographic characteristics: are girls, are enrolled in elementary school and have low socioeconomic status (Table 2). 
Table 1. Intake frequency of energy and energy-alcohol mixed drinks in Costa Rican youngsters.

\begin{tabular}{ccc}
\hline Intake frecuency & $\begin{array}{c}\text { Energy beverages } \\
\text { consumers n (\%) }\end{array}$ & $\begin{array}{c}\text { Energy-alcohol mixed } \\
\text { beverages consumers } \mathrm{n}(\%)\end{array}$ \\
\hline Never & $1869(70.10)$ & $2592(97.20)$ \\
Less than once a week & $3(0.10)$ & $1(0.04)$ \\
1 - 2 weeks & $352(13.20)$ & $35(1.31)$ \\
3 - 4 weeks & $199(7.50)$ & $11(0.41)$ \\
5 - 6 weeks & $138(5.20)$ & $6(0.22)$ \\
Everyday & $106(3.90)$ & $2667(100.0)$ \\
Total & $2667(100.0)$ & $22)$
\end{tabular}

$\mathrm{n}$ : number of consumers; \%: percentage.

In relation to the prevalence of the adverse results examined in the total study population, it ranges between $60.1 \%$ (low academic achievement) and $1.7 \%$ (cocaine consumption), being the intermediate prevalences, as follows (in decreasing order): cyberbullying (25.3\%), physical violence (fighting) (18.0\%), suicidal ideation (15.6\%), coital sex (10.0\%), school apathy (9.7\%), low educational expectation (9.5\%), deliberate self-harm (8.7\%), combined use of drugs that enhance the effects of illegal drugs (5.1\%), use of marijuana (5.0\%), use of knives or other weapons (4.5\%), perception of low risk of illegal drugs (4.0\%) and cement consumption (2.0\%) (Table 2).

The proportions of children and adolescents who consume energy drinks are significantly higher among each of the majority of the groups that have experienced the risk-taking behaviors examined in this study, compared to the proportions of children and adolescents that are consumers of energy drinks and who have not experienced these negative behaviors. For example, $62.2 \%$ of the study population that had experienced cocaine consumption is a consumer of energy drinks versus $29.4 \%$ who have not experienced cocaine use $(p<0.001)$. The exceptions of the risk associations were: combined use of drugs that enhance the effects of drugs; cyberbullying and sexual intercourse (Table 2).

In addition, differences were observed between the proportions of children and adolescents who consume energy-alcohol drinks who have experienced the negative behaviors examined, compared to the proportions of children and adolescents who consume energy-alcohol drinks who have not experienced these risk-taking behaviors. A statistically significant association was found between the combined use of medicines and energy drinks that enhances the effects of drugs. Near $28.5 \%$ of the study population that has experienced the combined use of medicines with drugs is also a consumer of energy-alcohol drinks versus $1.4 \%$ of the student's population that has not experienced the combined use of medicines that enhance the effects of drugs $(\mathrm{p}=0.003)($ Table 2$)$. 
Table 2. Frequencies of risk-taking behaviors and social and demographic characteristics of Costa Rican elementary schoolchildren and adolescents.

$\begin{array}{ccccc}\text { Energy beverages } & & \text { Energy-alcohol } & & \text { Total } \\ \text { consumers } & P \text { value } & \text { mixed beverages } \\ \text { consumers } & P \text { value } & \text { Non-consumers } & 1794(67.3 \%) & P \text { value } 2667(100.0 \%) \\ 798(29.9 \%) & & 75(2.8 \%) & & n(\%)\end{array}$

\section{Social and demographic characteristics}

- Gender:

$\circ$ Boys

○ Girls

- Education Level:

$$
\begin{aligned}
& \text { ○ Student/school } \\
& \circ \text { Student/high school }
\end{aligned}
$$

- Socioeconomic status:

$\circ$ Low $(\mathrm{L})$

$\circ$ Middle (M)

$\circ \operatorname{High}(\mathrm{H})$

\section{Risk-taking behaviors}

- Marijuana (Cannabis)

$$
\begin{aligned}
& \circ \text { Yes } \\
& \circ \text { No }
\end{aligned}
$$

$62(46.6)$

$736(29.0)$

0.006

$23(17.3)$

$52(2.0)$

- Cement (glue)

$$
\circ \text { Yes }
$$

$\circ$ No

0.015

$11(20.8)$

$64(2.4)$

0.069

$1780(68.1)$

0.002

$2614(98.0)$

- Cocaine

$\circ$ Yes

○ No

- Combined use of medicines that enhances the effects of legal and illegal drugs

$\circ$ Yes

$51(37.2)$

$\circ$ No

$747(29.5)$

0.316

$39(28.5)$

$36(1.4)$

0.003

$47(34.3)$

$1747(69.1)$

$<0.001$

$2530(94.9)$

- Low risk perception of illegal drugs
$\circ$ Yes
$48(45.3)$
$750(29.3)$

0.029
$13(12.3)$

$62(2.4)$
$55(51.9)$

0.387
$106(4.0)$

0.016

$2561(96.0)$ 


\section{Continued}

- Suicidal ideation

$\circ$ Yes

$\circ$ No

- Deliberate self-harm

$$
\begin{gathered}
\circ \text { Yes } \\
\circ \text { No }
\end{gathered}
$$

$174(41.8)$

$624(27.7)$

$103(44.2)$

$695(28.6)$

0.002

$16(6.9)$

$59(2.4)$

0.917

$114(48.9)$

$1680(69.0)$

$<0.001$

School apathy and academic achievement

- Unhappiness

$\circ$ Yes

$\circ$ No

- Academic achievement

- My average is low and I'm not doing well at all

$558(34.8)$

- I'm one of the best averages and I'm doing well

$240(22.6)$

$<0.001$

20 (1.9)

0.668

$991(61.8)$

$1604(60.1)$

$<0.001$

$803(75.5)$

$1063(39.9)$

- Educational expectation

$$
\begin{aligned}
& \circ \text { No } \\
& \circ \text { Yes }
\end{aligned}
$$

\section{Violent behaviors}

- Cyberbullying

○ $>3$ times/ 6 months

- Never or less than 3 times/6 months

$234(34.6)$

$564(28.3)$

0.093

$29(4.3)$

$46(2.3)$

0.843

$413(61.1)$

$1381(69.4)$

0.002

Physical violence (Fighting)

o $>3$ times/ 6 months

- Never or less than 3 times/6 months

$207(43.1)$

$591(27.0)$

$<0.001$

$40(8.3)$

$35(1.6)$

0.433

$233(48.6)$

$1561(71.4)$

$<0.001$

- Use of knives or other weapons

o $>3$ times/ 6 months

- Never or less than 3 times/6 months

$735(28.9)$

$<0.001$

$20(16.7)$

$55(2.1)$

0.071

$37(30.8)$

$1757(69.0)$

$<0.001$

$120(4.5)$

2547 (95.5)

- Risky Sex

$\circ$ Yes

$104(38.9)$

$694(28.9)$
$30(11.2)$

0.050

45 (1.8)
0.220
$133(49.8)$

1661 (69.2)
$267(10.0)$

$<0.001$

$p$ value: significant if $\mathrm{p}<0.05$; L: Low; M: medium; $\mathrm{H}$ : high; $\mathrm{n}$ : number of students. 
On the other hand, the proportions of children and adolescents who did not consume the two beverages examined were significantly higher among those who did not experience the negative behaviors studied, compared to the proportions of non-consumer children and adolescents who have experienced these negative behaviors. For example, $70.2 \%$ of the study population that had not experienced suicidal ideation is not a drink consumer versus $51.7 \%$ who have experienced suicidal ideation $(\mathrm{p}<0.001)$ (Table 2).

Regarding the logistic regression models, the results showed that youngsters who consumed energy drinks are more likely to present almost all the types of negative behaviors studied than non-consumers. Some negative behaviors examined in an adjusted or not adjusted way for possible confusion factors (gender, age and soors (cocaine, cement/glue and marijucioeconomic status), which were not statistically significant for energy drinks consumers were: combined use of medicines to get high, low risk perception of illegal drugs, school apathy, cyberbullying, low academic achievement and sexual intercourses. The adverse results with higher odds ratios (OR) were those related to lifetime addictive behaviana), followed in decreasing order by use of weapons, physical violence (fighting), low educational expectation, deliberate self-harm, suicidal ideation and low risk perception of illegal drugs (Table 3).

In the case of children and adolescents who consume energy-alcohol mixed drinks, the results of the logistic regression models showed that they are also more likely to present all the risk-taking behaviors studied than those who do not consume these mixed beverages. Even, the associations between energy-alcohol consumers remained statistically significant after adjustment for possible confusing factors: gender, age and socioeconomic status. For these consumers, the adverse results with higher probabilities (odds ratio or OR), in decreasing order, were: combined use of medicines to get high; cocaine consumption, consumption of cement/glue, consumption of marijuana, physical violence (fighting), use of weapons, suicidal ideation, deliberate self-harm, low educational expectation, sexual intercourses, cyberbullying and school apathy (Table 3).

\section{Qualitative phase:}

The majority of the participating student population perceived the intake of energy beverages as of low risk for their health and they don't analyze their components. Both, elementary and high school students agree that frequent consumption is because drinks have good flavors and nice logo designs. The dependence on energy drinks was also mentioned, since they had to be consumed daily and by fashion. Other intake reasons mentioned by the youngsters are related to the ability to stay awake and with more energy for longer periods of time in order to perform tasks such as: studying late at night for improving academic records, for better sports performance, for recreational meetings with their peers and to endure more the consumption of alcoholic beverages, as in these testimonies: 
Table 3. Crude and adjusted associations between regular intake of energy and energy-alcohol mixed drinks, with negative behaviors among children and adolescents.

\begin{tabular}{|c|c|c|c|c|}
\hline Risk-takingbehaviors & $\begin{array}{l}\text { Crudemodel } \\
\text { OR (95\% IC) }\end{array}$ & $P$ value & $\begin{array}{c}\text { Adjusted model }{ }^{\mathrm{a}} \\
\text { OR }(95 \% \mathrm{CI})\end{array}$ & $P$ value \\
\hline \multicolumn{5}{|l|}{ Marijuana (Cannabis) } \\
\hline Intake of energy drinks & $1.934(1.364-2.743)$ & $<0.001$ & $1.796(1.253-2.575)$ & 0.001 \\
\hline Intake of energy-alcohol mixed drinks & $9.739(5.761-16.463)$ & $<0.001$ & $5.649(3.198-9.981)$ & $<0.001$ \\
\hline \multicolumn{5}{|l|}{ Cement/glue } \\
\hline Intake of energy drinks & $2.172(1.201-3.926)$ & 0.010 & $1.913(1.046-3.499)$ & 0.035 \\
\hline Intake of energy-alcohol mixed drinks & $9.407(4.469-19.800)$ & $<0.001$ & $7.217(3.125-16.666)$ & $<0.001$ \\
\hline \multicolumn{5}{|l|}{ Cocaine } \\
\hline Intake of energy drinks & $2.459(1.298-4.659)$ & 0.006 & $2.073(1.082-3.971)$ & 0.028 \\
\hline Intake of energy-alcohol mixed drinks & $9.752(4.455-21.350)$ & $<0.001$ & $7.679(3.160-18.661)$ & $<0.001$ \\
\hline \multicolumn{5}{|l|}{ Combined use of drugs to get high } \\
\hline Intake of energy drinks & $1.049(0.782-1.406)$ & 0.751 & $1.099(0.784-1.541)$ & 0.583 \\
\hline Intake of energy-alcohol mixed drinks & $75.470(40.661-140.080)$ & $<0.001$ & $44.461(22.416-88.186)$ & $<0.001$ \\
\hline \multicolumn{5}{|l|}{ Perception of low risk of illegal drugs } \\
\hline Intake of energy drinks & $1.140(0.762-1.705)$ & 0.524 & $1.121(0.741-1.697)$ & 0.589 \\
\hline Intake of energy-alcohol mixed drinks & $4.693(2.494-8.830)$ & $<0.001$ & $3.058(1.555-6.016)$ & 0.001 \\
\hline \multicolumn{5}{|l|}{ Suicidalideation } \\
\hline Intake of energydrinks & $1.338(1.075-1.664)$ & 0.009 & $1.441(1.153-1.801)$ & 0.001 \\
\hline Intake of energy-alcohol mixed drinks & $2.577(1.591-4.174)$ & $<0.001$ & $3.395(2.035-5.664)$ & $<0.001$ \\
\hline \multicolumn{5}{|l|}{ Deliberate self-harm } \\
\hline Intake of energy drinks & $1.553(1.180-2.043)$ & 0.002 & $1.535(1.161-2.029)$ & 0.003 \\
\hline Intake of energy-alcohol mixed drinks & $2.447(1.385-4.322)$ & 0.002 & $3.249(1.766-5.977)$ & $<0.001$ \\
\hline \multicolumn{5}{|l|}{ Apathy and unhappiness at school } \\
\hline Intake of energy drinks & $1.185(0.906-1.551)$ & 0.215 & $1.161(0.881-1.531)$ & 0.289 \\
\hline Intake of energy-alcohol mixed drinks & $3.054(1.771-5.269)$ & $<0.001$ & $1.912(1.077-3.394)$ & 0.027 \\
\hline \multicolumn{5}{|l|}{ Cyberbullying } \\
\hline Intake of energy drinks & $1.029(0.854-1.239)$ & 0.764 & $1.010(0.836-1.220)$ & 0.920 \\
\hline Intake of energy-alcohol mixed drinks & $1.864(1.164-2.987)$ & 0.010 & $1.999(1.226-3.260)$ & 0.005 \\
\hline \multicolumn{5}{|l|}{ Physical violence (Fighting) } \\
\hline Intake of energy drinks & $1.708(1.394-2.092)$ & $<0.001$ & $1.523(1.238-1.875)$ & $<0.001$ \\
\hline Intake of energy-alcohol mixed drinks & $5.460(3.440-8.664)$ & $<0.001$ & $4.486(2.762-7.288)$ & $<0.001$ \\
\hline
\end{tabular}




\section{Continued}

Use of weapons

Intake of energy drinks

$1.745(1.206-2.524)$

Intake of energy-alcohol mixed drinks

Low academic achievement

Intake of energy drinks

Intake of energy-alcohol mixed drinks

Low educational expectation

Intake of energy drinks

Intake of energy-alcohol mixed drinks

Risky sexual behavior

Intake of energy drinks

0.433

0.226

Intake of energy-alcohol mixed drinks
$2.597(1.579-4.271)$

0.000
0.147

0.012

$1.962(1.163-3.310)$

$1.516(1.159-1.983)$

0.002

$2.577(1.418-4.685)$

0.002
$1.126(0.837-1.514)$

$1.216(0.886-1.668)$

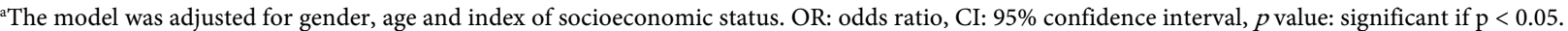

- "I use them when I go partying" (Male student of tenth grade of high school).

- "I drink it with vodka and tequila (...) besides of tasting very well, I can drink more, all night, without problem" (Male student of the tenth year of high school).

- "Yes, yes, they give you energy, they lower your stress (...) and you can enjoy the parties better" (Male student of sixth grade of elementary school).

On the other hand, some few students expressed that they were afraid to try energy drinks because of their possible repercussions on health: insomnia, headaches, hypertension, myocardial infarction and tachycardia.

\section{Discussion}

The intake frequencies of energy drinks, energy-alcohol mixed drinks and the behavioral problems examined in a representative sample of Costa Rican children and adolescents were determined. Likewise, the associations of each of these intakes with the negative behaviors were explored, being the first mixed study in Latin America in children and adolescents.

According to the bivariate analysis, it was found that children and adolescents who consume energy drinks had a greater risk of experiencing most of the risk-taking behaviors examined than their peers who do not consume these drinks. In the cases of consumers of energy-alcohol drinks, it is highlighted that they have a greater risk than non-consumers of this mixture to experience the use of medicines to enhance the effects of drugs.

This risk could be due to the fact that those who have consumed this mix, have overcome the fear of this combination and even experience pleasant sensa- 
tions, as stated by a male student of tenth year of high school: "I have tried them with alcohol, and it feels funny, as things move more around me." This leads to the assumption that these consumers would be more willing to use drugs and medicines that enhance their effects simultaneously, in order to perceive even stronger sensations.

Likewise, it should be considered that underestimation of risks is usual during adolescence and this underestimation is more likely when the youngsters want to give a good impression or when they believe they can control the effects or have low significant health damage expectations [18]. Based on the evidence in neuroscience, Steinberg [19] proposes that the dopaminergic areas, closely related to the so-called "reward circuits", would be involved in the social and emotional aspects that influence adolescents to take risky behaviors. These areas mature after the predominant cognitive areas (prefrontal cortex), which would explain biologically how the risks and possible harmful consequences are known and are equally involved in these behaviors.

Another important finding of the bivariate analysis is that behavioral problems are less frequent in the group of school and high school students who do not consume energy or energy-alcohol mixed beverages. Some expressions of young people who do not consume these drinks suggest that they are aware of the health risks involved in drinking them: "In the cans says that you cannot mix it with alcohol, but I know that some people do it and as it is not so often they endure it and for a long time until they are sure to fall there someday" (Male student of the tenth year of high school); "With alcohol it is dangerous to take a Red Bulp or something like that and then drink alcohol" (Female student of the tenth year of high school).

Students who consume energy-alcohol mixed drinks have more behavioral problems compared to their peers who are not consumers. Even this evidence of risk is evident among children and adolescents of high socioeconomic group compared to those of the lower socioeconomic group or with less economic resources, who probably have difficulty in buying energy drinks and alcohol as well, as the participants expressed it: "Sometimes I drink those beverages, but no way, those drinks are very expensive" (High school male student); “(...) If I could, I would always buy one, but I can't afford it (...)" (Male student of the fourth year of school).

Regarding the adjusted and not adjusted multivariate analyzes for possible confusing factors: gender, age and socioeconomic status, this study suggests that children and adolescents who consume energy drinks are more likely to present almost all the types of risk-taking behaviors studied than not consumers and that children and adolescents who consume energy-alcohol drinks are more likely to present all the negative behaviors studied than those who do not consume these blends. These findings agree with the results found in a representative sample of Slovak adolescents [20] and as reported by Jackson and Leal study [21], where some of these associations were particularly strong in the case of regular con- 
sumers of energy drinks/injections (in relation to occasional consumers or abstemious).

As mentioned, the associations remained statistically significant after adding gender, age, and socioeconomic status to the multivariate risk model for children and adolescents who consumed energy-alcohol mixed drinks, suggesting that this blend may not be the cause of confusion. Rather, the results suggest that there is a substantial association of alcohol and energy beverages with behavioral problems (including violence) in children and adolescents, regardless of sociodemographic characteristics (gender, age and socioeconomic status). It has been shown that the intake of alcohol has been the predictor of physical violence for both the adolescent perpetrator and for the adolescent victim of violence [22]. It can be assumed that energy drink intake enhances the effect of alcohol consumption and specific substances they contain such as caffeine, taurine and artificial sweeteners, increasing the aggressive behavior of adolescents [23]. In fact, in the study by Hyder et al. [24], the probability that young Australians under 25 years of age were involved in an incident of verbal aggression increased significantly with the consumption of energy drinks, while the probability of being involved in an incident of physical aggression increased significantly with the concentration of alcohol in the blood, the consumption of energy drinks and the use of illegal drugs.

In addition, the environments in which children and adolescents mix energy drinks and alcohol could increase the risks of experiencing the behaviors examined in this study related to disinhibition, aggression and "adrenaline" that could be felt by groups of young people meeting under the same conditions of intake in a common environment, such as a party or celebration, where they perceive various sensations, as described by the participants of the study: "It make you feel so crazy" (Male student of tenth year of high school); "Those drinks make me want to hit a race or party" (Male student of tenth grade of high school).

On the other hand, in the present study low educational expectation, deliberate self-harm and suicidal ideation were significantly associated with the intake of energy/energy-alcohol drinks. These results match with several studies that have reported negative effects of the consumption of energy drinks in the mood of adolescents [25] [26]. A Korean study also reported a significant association of energy drink intake with depressed mood and suicide attempt in adolescents [27] and another research showed that there is a significant association between increased caffeine intake and depression in adolescents [28].

Therefore, this research contributes greatly to the understanding of the onset and initial appearance of problematic behaviors during childhood and adolescence. Although the findings should be in a context and confirmed in other Latin American countries and latitudes. The theory tries to explain the results of risk-taking behaviors in the study population consuming energy or energy-alcohol beverages. Evidence suggests that the substances contained in these beverages 
can cause fluctuations in blood glucose levels, which in turn could lead to aggressive behaviors [9] [29] such as: use of weapons and physical violence (fighting). Holubcikova et al. [30] and Seifert et al. [9] report that adolescent energy drinks consumers turned out to be more vulnerable to deviations of mood, which could explain the low educational expectation, deliberate self-harm and suicidal ideation in these youngsters.

On the other hand, children and adolescents vulnerable to behave in a risky manner may also have a greater tendency to drink alcohol and swell the list of negative, premature and criminal behaviors that compromise health and favor crime, addiction, among other risk behaviors, such as addictive behaviors (cocaine, cement/glue and marijuana), low risk perception of illegal drugs [31] and sexual intercourse. The study of Scalese et al. [32] demonstrates that the life habits and risky behaviors of Italian school population aged 15 - 19 years old, consumers of energy and energy-alcohol mixed drinks, were positively associated with: going out with friends for fun, participating in sports, experiencing physical fights/accidents or injury, engaging in sexual intercourse without protection and being involved in accidents while driving. The perceptions found in this study reflect that consumers of energy drinks and alcohol do not feel confident in their talents and abilities, since they use these stimulants to perform their activities or interaction with their peers.

\section{Strengths and Recommendations}

This is the first mixed design study in Latin America that analyzes the intake of energy drinks and their mix with alcohol, the prevalence of risk-taking behaviors for health in children and adolescents and the quantitative associations between these consumptions with behavioral problems in this young population. Second, the sample of this study is large and representative of Costa Rica and third, confidentiality was guaranteed to children and adolescents participating and validated and anonymous instruments were used. Likewise, the social convenience probably did not affect the information provided on the intake of energy drinks, since in Costa Rica it is legal for children and adolescents to drink them; however, this situation is different with alcohol consumption. This research provides new and transcendent scientific knowledge, since children and adolescents who reported on the intake of energy drinks and those mixed with alcohol presented a higher risk of behavior problems than non-consumers, which implies the need for educational strategies aimed to expand the knowledge of children and adolescents about the adverse effects of these drinks. The adverse effect of energy beverage intake on behavior is comparable with alcohol intake, but the mixture of both was statistically significant and associated with all behavior problems analyzed, even adjusting for possible confusing factors. Efforts should be made to heighten awareness and education concerning the potential dangers of energy drink consumption among children and adolescents, particularly as it pertains to drug attitudes, diminished perceptions of substance use risk, physical violence, 
deliberate self-harm, suicidal ideation, sexual intercourses and cyberbullying. Educational technology, which is attractive and of daily use among youngsters should be used and emphasis should be placed on all behavior problems examined, which were associated with the combined use of energy-alcohol drinks in this study.

Future research should explore the causal pathways between the intake of alcohol and energy drinks and negative behavior outcomes in adolescents. More information is needed on the best way to minimize this potential threat to the health of children and adolescents.

Finally, public health policies should consider more demanding guidelines regarding the marketing of energy drinks (restriction of sales, clear warning labels, capping caffeine levels) and those that have alcohol, mainly controlling advertising aimed at children and adolescents, as has been done with the promotion and sale of tobacco cigarettes and the smoking prohibition in Costa Rica. Legislation and educational campaigns in this regard can be found on the official website of the Ministry of Health of Costa Rica. Public education may help prevent the adverse outcomes from energy and energy-alcohol mixed beverages.

\section{Study Limitations}

This study allows us only to make inferences regarding associations and not about causality. The data was based on self-records, which can be influenced by social convenience or memory bias. Besides, the sample does not allow the generalization of the findings for other cultures. The intake patterns of energy-alcohol drinks found in this investigation may not be the same ones for diverse groups of children and adolescents: e.g. athletes, racial/ethnic, sexual orientation and in youngsters who came from countries where alcoholic beverages and sexual intercourses are allowed at early ages. Sexual orientation was not explicitly collected.

\section{Conflicts of Interest}

The authors declare no conflicts of interest regarding the publication of this paper.

\section{References}

[1] Reissig, C.J., Strain, E.C. and Griffiths, R.R. (2009) Caffeinated Energy Drinks-A Growing Problem. Drug and Alcohol Dependence, 99, 1-10. https://doi.org/10.1016/j.drugalcdep.2008.08.001

[2] Keaver, L., Gilpin, S., Fernandez Da Silva, J.C., Buckley, C. and Foley-Nolan, C. (2017) Energy Drinks Available in Ireland: A Description of Caffeine and Sugar Content. Public Health Nutrition, 20, 1534-1539. https://doi.org/10.1017/S1368980017000362

[3] Johnson, S.J., Alford, C., Verster, J.C. and Stewart, K. (2016) Motives for Mixing Alcohol with Energy Drinks and Other Non-Alcoholic Beverages and Its Effects on Overall Alcohol Consumption among UK Students. Appetite, 96, 588-597. 
https://doi.org/10.1016/j.appet.2015.10.007

[4] Azagba, S., Langille, D. and Asbridge, M. (2014) An Emerging Adolescent Health Risk: Caffeinated Energy Drink Consumption Patterns among High School Students. Preventive Medicine, 62, 54-59. https://doi.org/10.1016/j.ypmed.2014.01.019

[5] Silva, A.C., De Oliveira Ribeiro, N.P., De Mello Schier, A.R., Pereira, V.M., Vilarim, M.M. and Pessoa, T.M. (2014) Caffeine and Suicide: A Systematic Review. CNS \& Neurological Disorders Drug Targets, 13, 937-944.

http://www.ncbi.nlm.nih.gov/pubmed/24923334 https://doi.org/10.2174/1871527313666140612123656

[6] Bonsignore, A., Sblano, S., Pozzi, F., Ventura, F., Dell'Erba, A. and Palmiere, C. (2014) A Case of Suicide by Ingestion of Caffeine. Forensic Science, Medicine, and Pathology, 10, 448-451. https://doi.org/10.1007/s12024-014-9571-6

[7] Ogawa,N. and Ueki, H. (2007) Clinical Importance of Caffeine Dependence and Abuse. Psychiatry and Clinical Neurosciences, 61, 263-268.

https://doi.org/10.1111/j.1440-1819.2007.01652.x

[8] Sánchez, S.E., Martínez, C., Oriol, R.A., Yánez, D., Castañeda, B., Sánchez, E., et al. (2013) Sleep Quality, Sleep Patterns and Consumption of Energy Drinks and Other Caffeinated Beverages among Peruvian College Students. Health, 5, 26-35. https://doi.org/10.4236/health.2013.58A2005

[9] Seifert, S.M., Schaechter, J.L., Hershorin, E.R. and Lipshultz, S.E. (2011) Health Effects of Energy Drinks on Children, Adolescents, and Young Adults. Pediatrics, 127, 511-528. https://doi.org/10.1542/peds.2009-3592

[10] Flotta, D., Micò, R., Nobile, C.G.A., Pileggi, C., Bianco, A. and Pavia, M. (2014) Consumption of Energy Drinks, Alcohol, and Alcohol-Mixed Energy Drinks among Italian Adolescents. Alcoholism, Clinical and Experimental Research, 38, 1654-1661. https://doi.org/10.1111/acer.12394

[11] Ilie, G., Boak, A., Mann, R.E., Adlaf, E.M., Hamilton, H., Asbridge, M., et al. (2015) Energy Drinks, Alcohol, Sports and Traumatic Brain Injuries among Adolescents. PLoS ONE, 10, https://doi.org/10.1371/journal.pone.0135860

[12] Grasser, E.K., Yepuri, G., Dulloo, A.G. and Montani, J.P. (2014) Cardio- and Cerebrovascular Responses to the Energy Drink Red Bull in Young Adults: A Randomized Cross-Over Study. European Journal of Nutrition, 53, 1561-1571. https://doi.org/10.1007/s00394-014-0661-8

[13] Kristjansson, A.L., Sigfusdottir, I.D., Frost, S.S. and James, J.E. (2013) Adolescent Caffeine Consumption and Self-Reported Violence and Conduct Disorder. Journal of Youth and Adolescence, 42, 1053-1062. https://doi.org/10.1007/s10964-013-9917-5

[14] Van Batenburg-Eddes, T., Lee, N.C., Weeda, W.D., Krabbendam, L. and Huizinga, M. (2014) The Potential Adverse Effect of Energy Drinks on Executive Functions in Early Adolescence. Frontiers in Psychology, 5, 457. https://doi.org/10.3389/fpsyg.2014.00457

[15] Terry-Mcelrath, Y.M., O’Malley, P.M. and Johnston, L.D. (2014) Energy Drinks, Soft Drinks, and Substance Use among United States Secondary School Students. Journal of Addiction Medicine, 8, 6-13. https://doi.org/10.1097/01.ADM.0000435322.07020.53

[16] Madrigal, J. (1997) La construcción de índices. Editorial UCR, San José, Costa Rica.

[17] Traynor, M. (2015) Focus Group Research. Nursing Standard, 29, 44-48. https://doi.org/10.7748/ns.29.37.44.e8822 
[18] Steinberg, L. (2007) Risk Taking in Adolescence: New Perspectives from Brain and Behavioral Science. Current Directions in Psychological Science, 16, 55-59. https://doi.org/10.1111/j.1467-8721.2007.00475.x

[19] Steinberg, L. (2008) A Social Neuroscience Perspective on Adolescent Risk-Taking. Developmental Review, 28, 78-106. https://doi.org/10.1016/j.dr.2007.08.002

[20] Holubcikova, J., Kolarcik, P., Madarasovageckova, A., Joppova, E., Van Dijk, J.P. and Reijneveld, S.A. (2017) Young Adolescents Who Combine Alcohol and Energy Drinks Have a Higher Risk of Reporting Negative Behavioural Outcomes. International Journal of Public Health, 62, 379-386. https://doi.org/10.1007/s00038-016-0862-4

[21] Jackson, D.B. and Leal, W.E. (2018) Energy Drink Consumption and the Perceived Risk and Disapproval of Drugs: Monitoring the Future, 2010-2016. Drug and Alcohol Dependence, 188, 24-31. https://doi.org/10.1016/j.drugalcdep.2018.03.022

[22] De Carvalho, A.P., Da Silva, T.C., De Melo Valença, P.A., Ferreira Santos, C.D.F.B., Colares, V. and De Menezes, V.A. (2017) Alcohol Consumption and Physical Violence among Adolescents: Which Is the Predictor? Ciência \& Saúde Coletiva, 22, 4013-4020. https://doi.org/10.1590/1413-812320172212.06172016

[23] Sankararaman, S., Syed, W., Medici, V. and Sferra, T.J. (2018) Impact of Energy Drinks on Health and Well-Being. Current Nutrition Reports, 7, 121-130. https://doi.org/10.1007/s13668-018-0231-4

[24] Hyder, S., Coomber, K., Pennay, A., Droste, N., Curtis, A., Mayshak, R., et al. (2018) Correlates of Verbal and Physical Aggression among Patrons of Licensed Venues in Australia. Drug and Alcohol Review, 37, 6-13. https://doi.org/10.1111/dar.12552

[25] Owens, J.A., Mindell, J. and Baylor, A. (2014) Effect of Energy Drink and Caffeinated Beverage Consumption on Sleep, Mood, and Performance in Children and Adolescents. Nutrition Reviews, 72, 65-71. https://doi.org/10.1111/nure.12150

[26] Childs, E. (2014) Influence of Energy Drink Ingredients on Mood and Cognitive Performance. Nutrition Reviews, 72, 48-59. https://doi.org/10.1111/nure.12148

[27] Park, S., Lee, Y. and Lee, J.H. (2016) Association between Energy Drink Intake, Sleep, Stress, and Suicidality in Korean Adolescents: Energy Drink Use in Isolation or in Combination with Junk Food Consumption. Nutrition Journal, 15, Article No. 87. https://doi.org/10.1186/s12937-016-0204-7

[28] Jin, M.J., Yoon, C.H., Ko, H.J., Kim, H.M., Kim, A.S., Moon, H.N., et al. (2016) The Relationship of Caffeine Intake with Depression, Anxiety, Stress, and Sleep in Korean Adolescents. Korean Journal of Family Medicine, 37, 111-116. https://doi.org/10.4082/kjfm.2016.37.2.111

[29] Harris, J.L. and Munsell, C.R. (2015) Energy Drinks and Adolescents: What's the Harm? Nutrition Reviews, 73, 247-257. https://doi.org/10.1093/nutrit/nuu061

[30] Holubcikova, J., Kolarcik, P., Madarasovageckova, A., Reijneveld, S.A. and Van Dijk, J.P. (2015) The Mediating Effect of Daily Nervousness and Irritability on the Relationship Between Soft Drink Consumption and Aggressive Behaviour among Adolescents. International Journal of Public Health, 60, 699-706. https://doi.org/10.1007/s00038-015-0707-6

[31] Dusseldorp, E., Klein Velderman, M., Paulussen, T.W.G.M., Junger, M., Van Nieuwenhuijzen, M. and Reijneveld, S.A. (2014) Targets for Primary Prevention: Cultural, Social and Intrapersonal Factors Associated with Co-Occurring Health-Related Behaviours. Psychology \& Health, 29, 598-611.

https://doi.org/10.1080/08870446.2013.879137 
[32] Scalese, M., Denoth, F., Siciliano, V., Bastiani, L., Cotichini, R., Cutilli, A., et al. (2017) Energy Drink and Alcohol Mixed Energy Drink Use among High School Adolescents: Association with Risk Taking Behavior, Social Characteristics. Addictive Behaviors, 72, 93-99. https://doi.org/10.1016/j.addbeh.2017.03.016 